
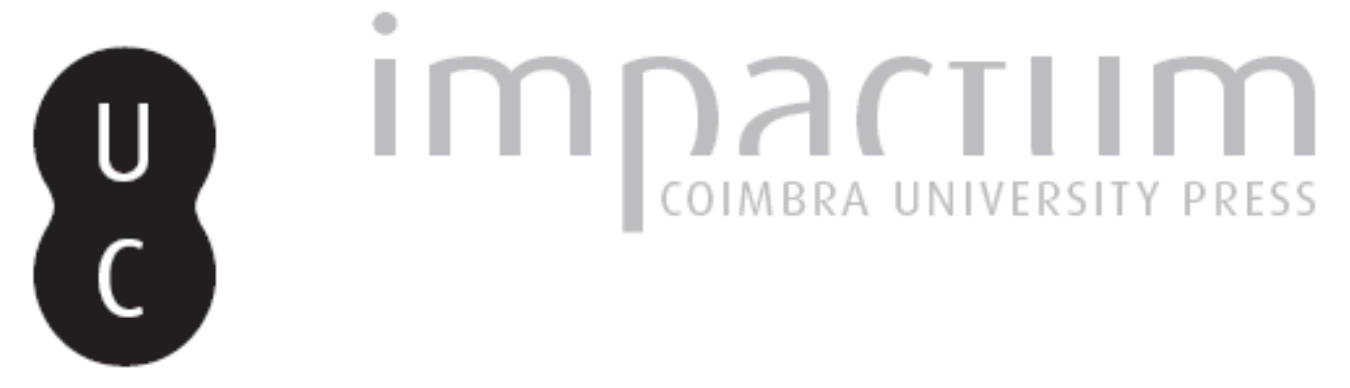

\title{
Unidade e pensamento no Parmênides e nos Elementos de teologia de Proclo
}

Autor(es): Bezerra, Cícero Cunha

Publicado por: Annablume Clássica

URL persistente:

URI:http://hdl.handle.net/10316.2/24481

DOI:

DOI:http://dx.doi.org/10.14195/1984-249X_5_9

Accessed : $\quad$ 26-Apr-2023 12:50:39

A navegação consulta e descarregamento dos títulos inseridos nas Bibliotecas Digitais UC Digitalis, UC Pombalina e UC Impactum, pressupõem a aceitação plena e sem reservas dos Termos e Condições de Uso destas Bibliotecas Digitais, disponíveis em https://digitalis.uc.pt/pt-pt/termos.

Conforme exposto nos referidos Termos e Condições de Uso, o descarregamento de títulos de acesso restrito requer uma licença válida de autorização devendo o utilizador aceder ao(s) documento(s) a partir de um endereço de IP da instituição detentora da supramencionada licença.

Ao utilizador é apenas permitido o descarregamento para uso pessoal, pelo que o emprego do(s) título(s) descarregado(s) para outro fim, designadamente comercial, carece de autorização do respetivo autor ou editor da obra.

Na medida em que todas as obras da UC Digitalis se encontram protegidas pelo Código do Direito de Autor e Direitos Conexos e demais legislação aplicável, toda a cópia, parcial ou total, deste documento, nos casos em que é legalmente admitida, deverá conter ou fazer-se acompanhar por este aviso. 

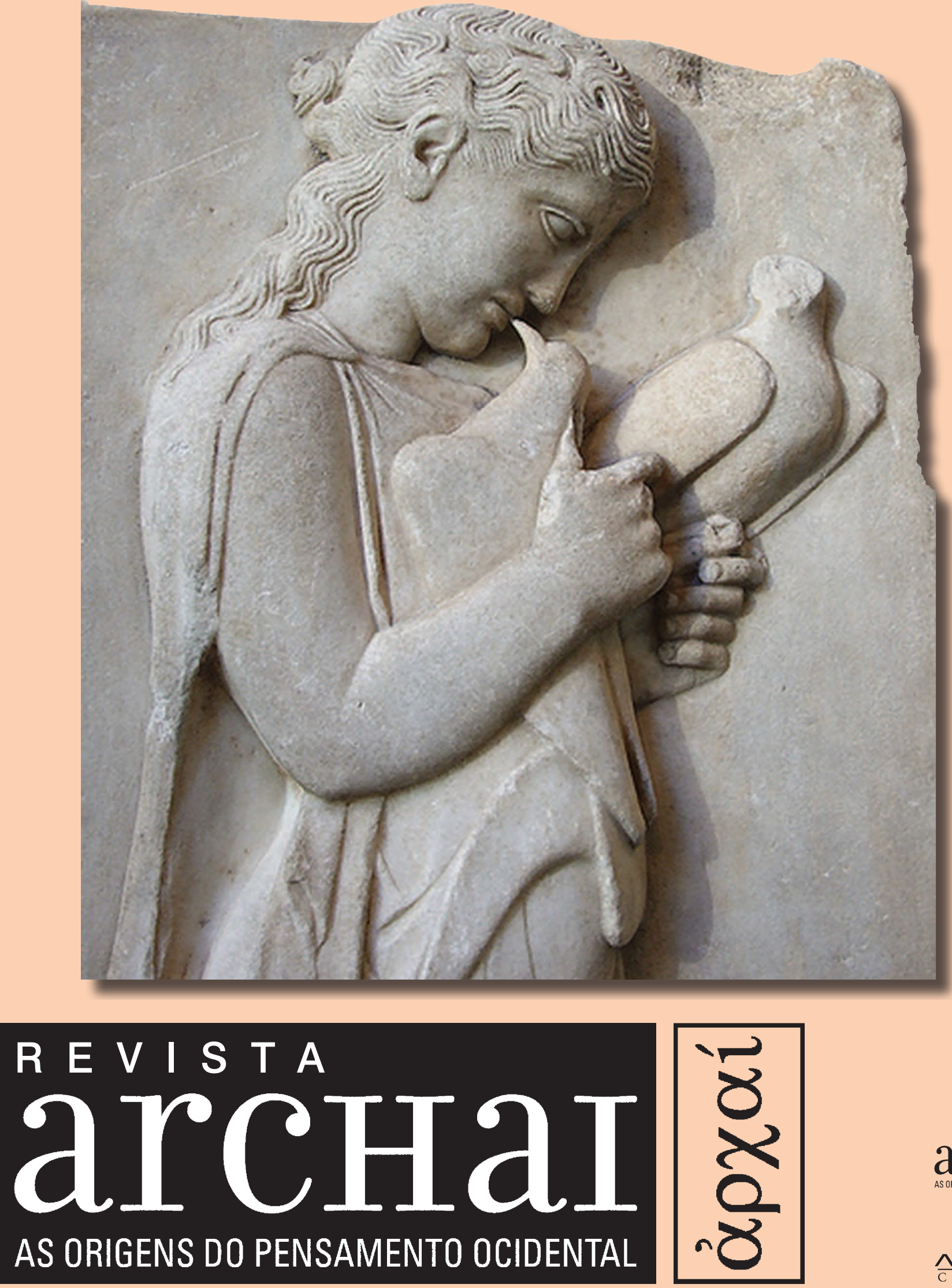


\section{UNIDADE E PENSAMENTO NO \\ PARMÊNIDES E NOS ELEMENTOS DE TEOLOGIA DE PROCLO}

RESUMO: Se tivéssemos que diferenciar o pensamento procleano frente ao plotiniano, talvez o caminho mais direto seria entender a estrutura hierárquica utilizada por ambos para definir a processão e a conversão do uno ao múltiplo. Embora a base, para ambos pensadores, seja a filosofia de Platão, a preocupação procleana em sistematizar de modo "orgânico" todos os niveis de participação nas henádes divinas o leva a postular um refinado sistema vertical em que cada realidade será pensada como monádes e, enquanto tal, diferenciadas uma das outras. 0 objetivo deste trabalho consiste, portanto, em compreender a estrutura procelana e sua relação com o pensamento entendido como transfiguração em que o real, mais que manifestação da unidade é expressão do jogo contínuo entre o uno e o múltiplo.

PALAVRAS-CHAVE: Proclo, Neoplatonismo, Filosofia, Negação.

ABSTRACT: If we would have to differentiate Proclean thought in relation to Plotinian thought, perhaps the shortest way would be to understand the hyerarchic structure used by them to define the procession and the conversion from the One to the multiple. Although the ground for both thinkers is Plato's philosophy, the concern to sistematize in an "organic" way all the levels of participation in the divine hennads leads Proclus to postulate a refined vertical system in which every reality is thought as a monad and, as such, one different from the others. The aim of this work consists in understanding the Proclean structure and its relation with thought, understood as a transfiguration in which reality, more than a manifestation of unity, is an expression of the continuous play between the One and the multiple.

KEYWORDS: Proclus, Neoplatonism, Philosophy, Negation

\section{Cícero Cunha Bezerra*}

* Universidade Federal de Sergipe

1. MARINUS, Vie de Proclus, trad. A.-ED. Chaignet in: Proclus, Commentaire sur Le Parmènide, Paris: Minerva, Tomo Premier, 1900, p.11

2. Proclo faleceu aos sessenta e cinco anos de idade. Idem, p. 6

\section{A inefabilidade do uno no Parmênides}

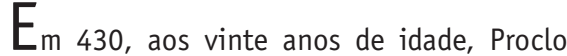
chegou, guiado pelos deuses, à Atenas. É com este tom iniciático que Marino narra a chegada do seu mestre ${ }^{1}$. Discípulo preferido de Plutarco e Siriano, Proclo se converteu, sem sombra de dúvida, no mais influente dirigente da Escola neoplatônica de Atenas. É bem verdade que as descrições feitas por biógrafos dos seus mestres requerem sempre certo cuidado. Não se pode negar, no entanto, o valor "simbólico" que alguns testemunhos transmitem com relação à filosofia e à personalidade de alguns filósofos. No caso de Plotino e Proclo, os relatos de Porfírio e Marino, são reveladores. Proclo possuía um temperamento extremamente comedido ao ponto de "emanar uma luz vivificante" dificil de ser descrita, segundo Marino, por palavras. Seu corpo e sua alma eram tão harmoniosos, graças a justiça definida como éxeis que, durante toda sua vida, só teria adoecido duas ou três vezes ${ }^{2}$. Verdade, justiça, coragem e temperança eram as virtudes próprias de um homem que fez da vida imagem e espelho do seu pensamento. Um pensamento marcado pela convergência entre o neoplatonismo e as sabedorias teúrgica e oracular. 
Toda pluralidade participa de algum modo do uno. É com essa assertiva que Proclo inicia sua obra Elementos de Teologia. Para os leitores da tradição neoplatônica é claríssima sua filiação ao pensamento platônico presente, de modo especial, na República e no Parmênides. A ideia de que sem o uno não é possível a pluralidade infinita dos seres, nem mesmo a multiplicidade enquanto tal, remonta inegavelmente às consequências das três hipóteses iniciais do Parmênides. Dado o limite desta exposição, faremos uma analise da processão no seu aspecto mais geral e, para tanto, torna-se indispensável uma breve recuperação dos principais argumentos referentes à divisão das hipóteses no Parmênides de Platão.

É comum se dividir o texto do Parmênides em duas partes: a primeira corresponde de 126 a e segue até o passo 136 e; a segunda, em 136 e até 166 c. Para este artigo, me interessa somente a segunda parte. Seguramente é nesta onde encontramos o núcleo das hipóstasis neoplatônicas tão importantes para a fundamentação do abra procleana e sua concepção do espírito como unidade entre pensante e pensado. Duas questões conduzem, de modo geral, o diálogo platônico, são elas: se o uno $e^{3}$, quais são as implicações? Se o uno não é, quais as consequências? Estas duas possibilidades em verdade implicam em quatro análises que se desdobram em oito hipóteses que serão analisadas detalhadamente ao longo da segunda parte desse Diálogo.

A questão já formulada na primeira parte, ou seja, "se as Formas são, cada uma, "um ser", em que sentido unidade e pluralidade são compatíveis?" será aprofundada na segunda parte do texto a partir da análise e consequências do sentido da expressão: se o uno é $e^{-4}$; ao fazer isto Platão busca compreender os vários sentidos que este termo possui e, somente entendendo as oito hipóteses ${ }^{5}$ como "oito maneiras" ou "modos" de se dizer que algo é uno, é possível uma análise do diálogo como um texto coerente e capaz de permitir a compreensão da longa tradição neoplatônica.

É certo que alguns comentadores preferem pensar que o texto platônico é somente um "jogo" no qual Platão simplesmente expõe as contradições da argumentação parmenídica. No entanto, Proclo, no Comentário ao Parmênides define o objetivo do diálogo platônico como "uma ginástica do olho da alma" ${ }^{\prime \prime}$. Nessa perspectiva, observa Wahl que o Parmênides é um exercício que segue os moldes da geometria, operando sobre as ideias e retirando as consequências mediante a destruição das hipóteses e mais, é uma homenagem de um profundo respeito e ao mesmo tempo, de uma profunda ironia rendida por Platão a seu mestre, Parmênides (CORNFORD, 1989, p. 69).

Vejamos, em linhas gerais, o argumento e as consequências da análise platônica do uno na primeira hipótese e, em seguida, a interpretação procleana. A ideia central consiste em pensar que, se 0 uno é, necessariamente, não é múltiplo e não pode ter partes. Diz Parmênides (137c):

- Pois bem, disse (Parmênides), se o uno é, não é certo que o uno não poderia ser múltiplo?

- Como poderia ser?

- Consequentemente, não pode ter partes, nem pode ser um todo.

Não é preciso dizer que qualquer sentido ou caráter diverso da unidade pressuporia uma alteração e o uno deixaria de ser uno para ser múltiplo já que teria algo distinto de si mesmo. Estamos diante de uma concepção de uno que não permite nenhum atributo além da sua unicidade.

As conclusões a que chegará Platão desta hipótese é que o uno pensado nesses termos é uma contradição. Vejamos por que:

1) se o uno não tem partes significa que o uno é sem princípio (apeiron), consequentemente, não terá limites, posto que os limites são definidos a partir do princípio e o final de algo.

Vale dizer que não ter limites, como observa Cornford, não deve ser entendido em um sentido puramente negativo, ou seja, não significa dizer que o uno tem uma "extensão" ilimitada, posto que seria contraditório com a definição.

2) Se o uno não tem partes carece de extensão e figura ou configuração (schkématos), já que uma figura é definida a partir de uma relação com os extremos. Para que algo seja, por exemplo, circular teria que ser compreendido a partir de uma
3. Sigo a observação de Jean Trouillard de que, dado o caráter transcendente, mas, também, imanente do uno, é melhor escrever com "minúscula".

4. Cornford analisa os muitos sentidos que na gramática grega têm os vocábulos uno e ser. 0 uno pode significar: 1) a unidade ou unicidade em geral; 2) a unidade de algo que tem unidade ou é algo; 3) o que tem unidade, ou seja, algo que é uno e, por último, 4) algo uno do qual estamos falando, enquanto se opõe a "outros unos" e à alguma outra coisa mais. A palavra "ser" é mais ambígua ainda. "Ser" pode significar: 1) o tipo de ser que pertence uma entidade, exista ou não; 2) uma entidade que tem ser no sentido de ser um termo que pode ser o sujeito de um enunciado verdadeiro;3) A essência ou natureza de uma coisa;4) a existência, e 5) o que tem existência, isto é, tudo o que existe. 0 comentador chama atenção para o fato de haver, ainda, o sentido copulativo de "é" e que "ée" pode significar "é o mesmo que". Com isso, Cornford quer atentar para a ambigüidade o termo "uno" possui e, paralelamente, ressaltar que não podemos entender "o uno" do diálogo como tendo sempre um mesmo sentido. 0 uno da hipótese I não é o mesmo que 0 da hipótese II, de maneira que, não podemos entender 0 uno como um " uno dos unos", nem tampouco, o Absoluto ou imagens desta natureza. Na verdade, a conclusão a que chega Cornford e que seguiremos, consiste em entender a crítica platônica como uma análise das ambiguidades que os termos uno e ser a partir das oito hipóteses que são em si oito sentidos diferentes. Cf. CORNFORD, 1989, 176.

5. Para esta análise do Parmênides, mantenho a interpretação de que o apêndice II, ao contrário do que defendem os neoplatônicos, não constitui uma terceira hipótese, mas é parte da segunda. De modo que o diálogo se dividiria em oito e não nove hipóteses.

6. Cf. BEZERRA, C.C. Compreender Plotino e Proclo, Petrópolis: Vozes, 2006, p. 105. 
equidistância entre as partes e seu centro, mas como o uno não tem partes, tampouco, terá centro, logo, não pode ser circular:

- Redondo é aquilo cujos extremos, em todas as partes, distam igualmente do meio.

- Sim.

- E reto é aquilo cujo meio está entre ambos extremos. (137 e)

Além do mais, se o uno, como vimos anteriormente, não tem figura nem extensão, tampouco estará em algum lugar.

3) 0 uno não está em nenhuma parte, nem em si mesmo nem em outro. Segundo Platão se 0 uno estivesse em outro, estaria rodeado por aquilo em que estivesse contido. Estaria Platão pensando na esfera bem redonda do proêmio de Parmênides? A questão seria: como algo que não tem partes, extensão ou figura, pode ocupar um espaço definido? Segundo o texto do diálogo, o uno da hipótese primeira, não pode de maneira alguma estar se quer em si mesmo, visto que, "é impossivel estar em algo e não ser rodeado por ele"(138b). Logo o uno não pode ser o que envolve e o envolto ao mesmo tempo.

A consequência desta afirmação é que:

4) o uno não é um corpo físico no espaço e, portanto, não está em movimento nem em repouso. A definição do uno como algo destituído de toda predicação revela que o uno, definido como tal, não pode nem mover-se, nem permanecer onde está, posto que não está em parte alguma. Vale ressaltar que a ideia de mudança ou alteração tem um sentido mais amplo que simplesmente uma mudança espacial.

Ao dizer que o uno, por carecer de propriedades físicas não muda, significa, em última instância, dizer que o uno não pode deixar de ser ele mesmo, visto que por não ter outros atributos, o uno não pode alterar-se. Diz Platão:

- Será então, trocando de local que vem a estar ora num lugar ora noutro, e é assim que se move? Sim, se é que se move. - mas não havíamos visto que era impossivel para ele estar em algo? - sim. (138d)

Logo o uno é imóvel com respeito a qualquer tipo de movimento.

- Mas, no entanto, o que jamais está em um mesmo lugar, nem permanece em repouso, nem em movimento. - não, não é possível. - Logo, o uno, segundo parece, nem se mantém em repouso nem se move. - isso, é o que parece. (139b)

De modo que Platão com a primeira hipótese demonstra que, começar uma discussão pressupondo que o uno é uno e nada mais, culmina inevitavelmente, em uma contradição, pois impossibilita qualquer tipo de discurso, seja sobre o próprio uno, seja sobre as demais coisas. 0 uno tratado na hipótese primeira é um uno isolado, separado de toda existência e de toda relação. 0 uno assim compreendido, não é o mesmo, nem diferente de si mesmo ou de outro (139c).

A impossibilidade do uno ser o mesmo que si mesmo e diferente do outro, é uma consequência imediata da definição do uno como simplesmente uno. Platão segue uma argumentação extremamente lógica a partir da definição dada no inicio do diálogo. Diz Parmênides no passo 139e-140b:

Resulta assim, que o uno não poderá ser nem diferente nem o mesmo, nem com relação a si mesmo, nem a algo diferente.

- Com efeito, não.

0 que quer dizer o termo semelhante? Para Platão, semelhante pode ser pensado como algo que tem um caráter de idêntico. De modo que à semelhança associa-se a mesmidade. Isto significa dizer que duas coisas são semelhantes sempre que tenham os mesmos atributos. Mas o uno, pensado nesses termos, não tem nenhum outro caráter que não seja a unidade mesma, logo, não pode ser semelhante a nada visto que pressuporia o diferente de si com o qual compartiria atributos semelhantes.

Por conseguinte, o uno não pode ser semelhante a outro nem a si mesmo, nem tampouco 
dessemelhante, visto que se diz que "dessemelhante é algo que se pode dizer com verdade que é diferente de si mesmo ou de outro" (140b). A implicação lógica da negação da mesmidade como atributo do uno, da primeira hipótese, significa que, assim como ele não pode ser diferente nem muito menos semelhante a si ou a outro, não pode ser igual ou desigual, visto que a igualdade pressupõe ser o mesmo que ou ter o mesmo que, mas como vimos anteriormente, o uno não tem o caráter do mesmo:

Logo, se não participa de uma medida, nem de muitas nem de poucas, nem participa absolutamente do mesmo, jamais, ao que parece, será igual bem a si mesmo nem a outra coisa. De outra parte, não será nem maior nem menor que si mesmo nem a algo diferente. (140 d)

Portanto, si o uno não possui os caracteres de ser o mesmo, o diferente, o igual nem o desigual, não pode estar no tempo. Pressupor temporalidade significa aceitar a mutabilidade; significa dizer que algo é jovem ou velho e mais, significa dizer que algo tem que tornar-se mais velho que si mesmo e ao mesmo tempo, mais jovem que si mesmo, pois como afirma Parmênides:

0 que chega a ser mais velho que ele mesmo chega a ser, ao mesmo tempo, também, mais jovem que ele mesmo, si é que tem que ter algo com relação ao qual chegue a ser mais velho (141b).

Platão simplesmente ressaltaria que pelo fato do uno não ter mesmidade implica, necessariamente, que não há um parâmetro que se possa utilizar para dizer que o uno está no devir temporal, pois todo processo de devir relaciona-se a algo que "é" e "deixa de ser" o "mesmo" ${ }^{7}$. Entretanto, o uno da hipótese primeira, não possui a mesmidade posto que sua unicidade o impede. Como bem ressalta Cornford, dizer que "x é uno" não é a mesma coisa que dizer que " $x$ " é o mesmo que si mesmo", logo o uno do poema de Parmênides por ser uno absolutamente, não possui nenhum outro caráter e não pode ser ou chegar a ser mais velho ou mais jovem. Vejamos a seguinte passagem:
E então? Parece possível que o uno possa ser mais velho ou mais jovem ou ter a mesma idade que algo? $E$ por que não? - Porque, se tivesse a mesma idade que ele mesmo ou que outro, participaria de uma igualdade de tempo e de uma semelhança, mas dissemos que o uno não participa delas, nem da semelhança nem da igualdade. - De fato dissemos. (141e).

Todas as conclusões da primeira hipótese parecem conduzir, portanto, conduzem inevitavelmente para uma visão negativa de um uno isolado de toda relação de alteridade. Isso significa dizer que Platão permite, com sua análise, a afirmação, pela negação, de um não-ser superior ao ser e que será compreendido pelos neoplatônicos como o Bem superior a todas as coisas presente na República ${ }^{8}$. Vejamos, agora, o reflexo da interpretação platônica nos Elementos de Teologia.

\section{0 uno como princípio puro (autoén)}

Nos Elementos de Teologia Proclo realiza sua análise tomando como ponto de partida a afirmação de que sem o uno, nenhuma plurali-dade é possível. 0 argumento é platônico e pode ser resumido do seguinte modo: para que a pluralidade seja, é necessário um princípio que a defina tanto como multiplicidade, quanto soma de partes, já que a negação desta afirmação culminaria no regresso ad infinitum dado que cada parte seria infinitamente múltipla e, consequen-temente, a multiplicidade não poderia ser pensada enquanto multiplicidade mesma. Diz ele: “Em efeito, não participando de alguma maneira da unidade, nem na totalidade, nem em cada um dos seus componentes, será tanto na totalidade quanto nas suas partes infinito" (Elem. Teol. 1). Assim sendo, a pressuposição da existência do uno é condição para a existência do múltiplo. Estamos diante do que W. Beierwaltes chama de "unidade relacional" que significa pensar o uno enquanto fundamento determinante e delimitante de tudo o que é (BEIERWALTES, 1992, p.24).

0 fato da participação das coisas na unidade pressupor, como dissemos, o uno, é, para Proclo, a demonstração de que, do ponto de vista originário, o uno escapa ao processo de participação no
7. Corford observa que Proclo $(\mathrm{IV}, 232)$ ao interpretar esta passagem, conservou a explicação de Siriano que distingue duas formas de conceber o tempo. 0 primeiro seria pensar que algo avança por uma linha reta de um ponto a outro. A outra consiste em transladar em torno de um círculo onde o princípio sempre seria o fim. Deste modo, sempre que uma coisa se distancia de seu inicio torna-se mais velha mas sempre que se aproxima de seu fim torna-se mais jovem, posto que aproximar-se de seu princípio é rejuvenecer. Ao que parece, segundo Cornford, Siriano entendeu a passagem citada como uma referência ao ciclo periódico das almas divinas, mas ressalta o comentador que a hipótese segunda que Platão " parece considerar o tempo como uma linha reta, não como um círculo, e o mesmo Proclo retoma uma interpretação mais geral que não envolve a periodicidade".Cf. CORNFORD, 1989, 197.

8. WAHL, 1951, p.100. 
sentido de que todo ser é, na medida em se unifica, no entanto, precisamente por se unificar, não é uno. 0 uno, ao contrário, não pode ser uno e não-uno. Estamos, assim, na consequência direta da primeira hipótese, convertida em hipóstase, a saber: o uno absolutamente transcendente, mas fundamental-mente imanente enquanto determinante e delimitante de todas as coisas. Vejamos esta passagem do capítulo 4: "Pois se fosse idêntico ao unificado, o uno seria uma pluralidade infinita, e paralelamente, cada uma das partes que compõem o unificado" (Elem.Teol. 4).

A questão da anterioridade ou prioridade do uno sobre a multiplicid0ade fica evidenciada no capítulo quinto a partir de três possibilidades: a) a multiplicidade seria anterior ao uno; b) a multiplicidade coexistiria com o uno; c) o uno e a multiplicidade seriam contrapostos. Eis os passos da análise.

a.a) No caso da multiplicidade ser anterior ao uno teríamos a inversão do que dissemos anteriormente, ou seja, seria o uno que participaria da multiplicidade. No entanto, como a multiplicidade não pode ser, sem a existência daquilo que the confere realidade, nem muito menos o uno, pois caso participasse da multiplicidade não poderia ser "uno", dado que não existiria, fica evidente que a multiplicidade não é anterior ao uno.

b.b) Na hipótese de que o uno coexista com a multiplicidade teríamos a seguinte situação: 0 uno não seria múltiplo nem o múltiplo uno. Coexistiriam simultaneamente como dois princípios naturais. Para Proclo, é impossível que a pluralidade seja infinita em si mesma, isto é, que cada um dos seus componentes ou partes seja infinitos não-unos, diz ele:

A pluralidade participará do uno por sua própria natureza, e não se encontrará nada nela que não seja uma. Pois se ela não é uma, ela será infinidade de infinitos, como se mostrou. Por consequência ela participará do uno de todas as maneiras" (Elem. Teol. 5).

0 mesmo raciocínio se aplica, também, ao uno, isto é, se participa da multiplicidade permanecendo uno em natureza e não uno por participação, a consequência, seguindo o modelo anterior, é que o uno se multiplicará infinita-mente. c.c) Supondo que o uno e a multiplicidade sejam contrapostos, isto é que o uno enquanto uno não é múltiplo e o múltiplo enquanto múltiplo não é uno, o que decorreria disto?A conclusão segue o mesmo direcionamento já exposto no início dos Elementos, a saber: o uno e a multiplicidade, enquanto si mesmas, serão unas, mas duas por princípio. Logo, para Proclo, deve haver uma terceira realidade que uniria as duas em suas relações. Como condição para tal, o que é anterior a uno e a multiplicidade deveria ser ou uno ou não-uno. Sendo não-uno seria ou múltiplo ou nada. Para Proclo, ambas hipóteses são superadas, posto que, a multiplicidade não pode, como já vimos, preexistir ao uno e, do mesmo modo, o nada já que o nada não poderia ser o princípio conciliador entre o uno e o múltiplo. Logo, o princípio último é uno em si do qual tudo procede.

Ao argumento da preexistência do uno soma-se, talvez por uma influência da tradição de intérpretes que entenderam o pensamento aristotélico como expressão do platonismo, a uma série de afirmações que tem como base o princípio da causalidade entendido como o Bem que unifica todas as coisas. Vejamos os principais pontos.

a) Todo ser que produz outro é de ordem superior ao seu produto. A defesa desta assertiva se desdobra em três outras hipóteses:

a.a) a causa ou é superior; a.b) ou é inferior; a.c) ou é igual.

Proclo inicia sua análise a partir do terceiro ponto (a.c) e diz:

ou bem ele teria o poder de produzir algo ou seria completamente estéril. Mas, sendo estéril fica demonstrado ser inferior ao seu produtor e desigual com aquilo que é fecundo e que possui o poder de produzir. Se, ao contrário, o produto é produtor de outros seres, ou bem ele produz um ser igual a ele e, sendo assim, todo derivado é igual a ele mesmo ou bem ele produz um efeito que lhe é desigual e se desfaz a igualdade entre produto e produtor (Elem. Theol. 7). 
A conclusão é que é impossível tanto que o produto seja igual ao seu produtor quanto o produtor ser inferior ao seu produto, mas ele é exatamente aquilo que, de fato, sustenta a existências dos seres gerados. A passagem do argumento causal para o da unidade primeira é feito de modo bastante coerente com a filosofia platônica da República. "Todos os seres tendem para o bem (Elem.Theol. 8)" e, neste sentido, o bem é o que está além de todos os seres. A identidade entre o uno e o bem em si está consolidada. Naturalmente, o bem desejado pelos seres é um bem particular enquanto que o bem primordial é sumamente bem. Nenhum outro caráter pode ser acrescentado ao bem puro e simples.

A autonomia (aútarkes) é um principio também definidor da anterioridade do uno frente a multiplicidade. Seguindo a lógica da processão (próodos) neoplatônica, Proclo afirma que o desejo pelo bem vem sempre marcado pela carência e, nesse sentido, a dependência do que é posterior com relação ao anterior ${ }^{9}$ é a marca do processo infinito da geração a partir do uno superior a todo ser.

No fundo, é o germe da teologia negativa que se estrutura mediante a negação de toda positivização do uno frente, até mesmo, ao bem, objeto de desejo de todos os seres. 0 uno, embora tomado como bem em si, não é um bem particular nem muito menos uma ideia ou paradigma. Estamos tratando de supra negações (hypera-pophasesin), ou seja, a existência, na própria alma humana, de uma raiz negativa que, ao mesmo tempo em que deseja 0 bem como fonte, reconhece a exigência de negação imanente ao próprio princípio.

Como podemos ver, entre a autonomia e o uno existe um parentesco que embora aproxime os seres auto-suficientes do seu princípio os mantêm distantes. Ao uno não pode ser aplicado o atributo de autônomo, posto que, autônomo é o que está repleto de bem e não o bem primordial (Elem. Theol.10).

No texto dos Elementos, Proclo expõe detalhadamente a processão e a conversão do uno ao uno a partir de quinze pontos que vão do capítulo 25 ao 39. São eles:

25. De todo princípio perfeito procede tudo o que é capaz de engendrar imitando o único princípio universal.
26. Toda causa que produz, mantém-se, em si mesma, imutável.

27. Todo produtor produz seus derivados por perfeição e superabundância de poder.

28. Todo produtor faz subsistir seres semelhantes a ele antes de produzir o dessemelhante.

29. A lei da processão é a semelhança dos derivados com relação aos seres primeiros.

30. Tudo o que é produzido imediatamente por um princípio permanece na causa e procede dela.

31. Todo ser que procede de um princípio se converte, em seu ser, para aquele de onde procede.

32. A lei de toda conversão é a semelhança, ao término da conversão, de todos os seres.

33. Todo ser que procede de um princípio, e se converte para ele, possui uma atividade cíclica.

34. Todo ser que se converte por natureza orienta sua conversão para o princípio o qual ele dever a processão da sua substância.

35. Todo efeito, ao mesmo tempo que permanece em sua causa, procede dela e ser converte para ela.

36. De todos os seres que se multiplicam, na processão, os primeiros são mais perfeitos que os segundos, os segundos mais perfeitos que os últimos.

37. De todos os seres que se multiplicam, na conversão, os primeiros são menos perfeitos que os segundos, os segundos menos perfeitos que os últimos.

38. Tudo que procede de várias causas emprega, na conversão, os mesmos termos que na processão.

39. Todo ser se converte ou bem segundo somente sua substancia (ausiodos), ou bem segundo seu modo vital (zotikos) ou ainda, segundo o modo noético (gnostikos).

Em linhas gerais, Proclo está fundamen-tando, a partir das ideias de causalidade e processão, a geração infinita dos seres a partir da primeira hipóstasis (o uno) como um ciclo que tem no próprio uno seu princípio e fim. 0 importante para nosso tema aqui, é perceber, em Proclo, a natureza transcendente do uno primordial. Diz ele: "Além dos corpos está a substancia psíquica, mais além
9. É imprescindível para a compreensão dessa dependência 0 estudo das triadas como mediação ativa. Sobre a temática ver: BEIERWALTES, W. Proclo $i$ fondamenti della sua metafísica, trad. Nicoletta Scotti, Milano: Vita e Pensiero, 1990, p. 71. BEZERRA, C.C. Compreender Plotino e Proclo, op.cit. p. 118. 
de todas as almas está a ordem do espírito (he noerà phúsis) e mais além de todas as substâncias pensantes (noeron hupostáseon) o uno (Elem. Theol. 20)."

Mas como podemos aproximar o texto dos Elementos e o Parmênides?

\section{A 'unimultiplicidade' do uno que é}

A questão condutora da segunda hipótese do

10. De acordo com Cornford que traduz metéxein por participar, mas por ter parte.

11. Cornford entende está divisão como um ato mental de distinguir os dois elementos no "ente uno. Cf. CORNFORD, 1989, p.211. Wahl, por sua vez, afirma que do mesmo modo que na primeira hipótese Platão nega o uno eleático, na segunda, faz o mesmo com a concepção do uno de Leucipo e Demócrito. Segundo o comentador os filósofos de Abdera como qualquer outro megárico, não faz mais que remontar-se ao uno eleático. De manera que destruido o materialismo eleático e megárico, surge o véritable idéalisme platonicien. Cf. WAHL, 1951, p.157. os atributos ou caracteres que foram dispensados
Parmênides é: " se o Uno é", não pode ser e não $\operatorname{ter}^{10}$ ser. Platão começa está hipótese questionando justamente o dogma eleático da univocidade do ser frente à possibilidade da existência da pluralidade. Mediante um refinado argumento lógico, dispensa a visão unilateral do uno fechado em si mesmo, por um uno que possui, em princípio, dois atributos: a unidade e o ser.

Se na primeira hipótese não se podia dizer nada acerca do uno, a partir da segunda é possível pensar e deduzir a pluralidade das coisas. 0 uno da segunda hipótese, é um uno que se opõe diretamente ao Uno da hipótese primeira já que possui todos anteriormente. Diz Platão:

- A hipótese agora não é "se o uno é uno" o que se seguiria?", mas "se o uno é". Não é assim? (142 c)

0 diálogo segue os mesmos pressupostos metodológicos do inicio, ou seja, pensar as consequências que se seguem de uma afirmação do tipo "se um uno é". A questão formulada neste momento consiste em compreender o "é" como algo que implica " ter ser" e consequentemente, como algo que "existe". Vale ressaltar que ser e uno, são distintos, ou seja, dizer que o uno "é" uno, não é o mesmo que dizer que " um uno é". De modo que o ser deve ser compreendido em um sentido amplo.

Cornford observa que sobre este ser se pode fazer qualquer tipo de enunciado, inclusive que não existe (CORNFORD, 1989, p.207). Sendo assim, ao dizer que o uno é, estamos dizendo que o uno tem ser. Existência aqui não significa, ainda, uma existência temporal, mas que existe enquanto algo passivel de um enunciado verdadeiro (142 d):
Do seguinte modo. Se é se diz de um uno enquanto que é, e uno se diz do que é uno enquanto uno, e se a essência e o uno não são o mesmo mas sim pertencem ao mesmo, àquilo que hipotetizamos, a saber, o uno que é, não será necessário que ele, o uno que é, seja um todo e que tenha partes tanto o uno quanto o ser?

A conclusão que retiramos é que o uno é um todo composto de partes, pois, ser e uno não são o mesmo e isso significa dizer que "é" pertence a este uno que é e que "uno" pertence a este ser que é uno; chegamos, portanto, à conclusão de que ambos pertencem a mesma coisa. Ao afirmar 0 aspecto múltiplo do uno ( unidade e ser), Platão estabelece definitivamente a visão de um uno complexo e também múltiplo. Esse fato podemos constatar na passagem 142e-143a onde lemos que as partes (unidade e ser) nunca carecerão uma da outra, visto que, cada parte consiste, pelo menos, em duas partes, posto que o uno sempre tem ser e este por sua vez, sempre tem unidade. De modo que 0 "ser uno" tem que ser ilimitado.

A negação efetuada na primeira hipótese da possibilidade de uma evolução do tipo pitagórica, mediante os números, vê-se agora superada pelo restabelecimento do par de contrários (Limite e Ilimitado). 0 uno já não se limita a ser somente um uno, mas também tem ser e por sua vez, suas partes podem ser dividida de forma ilimitada ${ }^{11}$.

De modo que Platão se refere à unidade enquanto ideia que sempre conduz para uma multidão infinita de uno e ser já que pensar o uno é pensar ser + unidade ad infinitum. Do ponto de vista de uma "divisão" do uno chegamos a uma infinita "soma" de partes. Do mesmo modo, se olharmos do ponto de vista de uma "adição e multiplicação" também chegaremos a uma multidão de partes já que se um uno é, é necessário também que o número seja (144a).

0 argumento da adição e multiplicação é bastante claro e segue o mesmo raciocínio de antes, ou seja, se o uno é diferente do ser é porque algo os faz distintos. Este algo não é o uno em si, nem muito menos o ser, mas a diferença, dito de outra forma, o que faz o uno ser diferente do ser é serem eles diferentes um do outro. Sendo assim, ser uno implica ser dois. 
Estabelecido, portanto, a implicação lógica entre a unidade e a multiplicidade, fica fácil deduzir que se existem dois forçosamente, existe duas vezes dois ou como expressa o texto, dois é duas vezes um e três, três vezes um (143 e).

De maneira que, haverá múltiplos ímpares de pares e múltiplos pares de ímpares. Esta afirmação consiste de fato na formalização da pluralidade ilimitada. Platão desenvolve sua argumentação a partir da formulação "o uno é" e chega, mediante uma rigorosa reflexão, à pluralidade das coisas. Diz ele:

Mas, se o número é, também é a pluralidade e uma multiplicidade ilimitada de coisas são. Ou o número não resulta ilimitado em multiplicidade e participa do ser? (144a)

Estamos assim, frente à geração pitagórica. Se o número é, é forçoso que hajam muitas coisas. 0 ser se distribui por todos os entes de modo que não faltará a nenhum deles. Que a unidade permanece dividida em todas as partes é a conclusão que justifica estar ela presente em todos os seres ao mesmo tempo. Por ser o uno um composto de ser e unidade, que por sua vez, são infinitamente divisíveis, este também é múltiplo e ilimitado em número.

Em concreto, Platão radicaliza sua crítica à teoria eleática do uno. Se para Parmênides do poema, a existência do uno implicava necessa-riamente a negação do múltiplo, já que a pluralidade dos seres the era irracional, para Platão não há contradição entre o ser-uno e a pluralidade de seres. Por ser 0 uno uma totalidade de partes, consequentemente, um todo, este é limitado, mas, por ser o todo e também as partes, este é numeroso indefinidamente. Logo, o uno da segunda hipótese, é uno e múltiplo.

De maneira que a unidade, entendida como a Forma em si, possui pelo menos três caracteres distintos, são eles: é, enquanto Forma, existe e é diferente de sua existência (CORNFORD,1989, p.216). Ressalta Cornford que a única maneira de superar as consequências negativas retiradas da primeira hipótese, é pressupor a divisibilidade e participação da unidade entre muitas coisas, do contrário, negar esta divisão significaria resgatar todas as implicações negadas anteriormente, bem como, aniquilar o discurso sobre o uno.

Dito isso, finalmente se pode atribuir todos os caracteres abstraídos anteriormente do uno. A argumentação é extremamente clara e precisa. Se o uno é um todo, como vimos anteriormente, teria princípio, meio e fim. Como consequência disto, o "uno que é" teria também figura visto que se tem metade, tem extremos. Vale ressaltar, que o fato de se poder atribuir uma figura, seja redonda, reta ou uma mistura de ambos, não significa que ele tenha que ter figura, mas que se pode acrescentar sem que haja nele nada ilógico.

0 próximo passo é saber se o uno que tem figura e, portanto, pode ocupar um espaço, está em si mesmo ou em outro. 0 argumento se divide em dois pontos, a saber: (a) cada parte está, por certo, no todo; (b) nenhuma está fora dele, e (c) todas as partes estão contidas por ele. (145b). Segundo este raciocínio, o uno, que é um todo, tem que estar em si mesmo, do contrário, implicaria estar em umas partes e outras não, algo impossível se o pensamos como totalidade. No entanto, o todo não está nas partes, nem em todas as partes nem em uma parte (145d). Parece contraditório o segundo argumento, mas é uma consequência lógica, ou seja, o uno não pode estar em uma parte, posto que como diz Platão : se o todo estivesse em alguma das partes, o maior estaria contido no menor, o que é impossivel. Esta passagem é importantíssima para que compreendamos a argumentação procleana sobre a supra essência divina que, por ser uno, não é parte de uma multidão nem conjunto de partes. Leiamos o texto platônico:

- Se o todo, então, não está nem em muitas nem em uma nem em todas as partes, não é necessário que esteja em alguma outra coisa, ou bem que não esteja em nenhum lado?

- É necessário.

- Se não estivesse em nenhum lado, não seria nada; mas, posto que é um todo, dado que não está em si mesmo, não é necessário que esteja em outra coisa? (145 e) 
12. Esse é um das poucas passagens e que Cornford classifica como uma aparente falácia, mas o que quer de fato Platão é mostrar que as expressões em si e no outro são ambíguas, refutando assim a tese de Zenão segundo a qual uma coisa não pode ter dois caracteres contrários. Cf. CORNFORD, 1989 ,

$$
\text { p. } 228 .
$$

13. Cornford observa que Platão antecipa a demonstração que leva a cabo no Sofista (255e) e que compreende os outros como não uno, mas que isso não significa dizer que não tenham unidade, mas que "são numericamente diferentes de uma coisa com a que os contrastamos em qualidade de outras coisas.Cf. CORNFORD, 1989,
A consequência desta reflexão é que o ente uno tanto permanece em repouso, como em movimento já que, como vimos antes, ele possui o caráter de estar em si mesmo e em outro. 0 que está em si mesmo está sempre no mesmo lugar, logo sempre em repouso, mas o que está em outro, nunca pode estar no mesmo, logo, tem que estar em movimento ${ }^{12}$. Com isso, Platão demonstra que o uno da hipótese II, tem ser, é múltiplo, pode possuir extensão, figura, movimento e repouso. Estas conclusões levam Cornford a afirma que Platão resgata a evolução pitagórica mediante a passagem dos números aos corpos físicos no espaço. Este uno diferentemente do uno parmenídico do poema, está livre do irracionalismo e do isolamento derivado da visão monista do Ser.

Platão de uma certa maneira, "salvaria" o devir heraclítico e inauguraria uma nova visão do ser que possibilitaria o discurso filosófico. 0 "uno que é" é um uno passível de atributos e qualidades sensiveis sem que isso contradiga sua natureza. Contra à afirmação parmenidica de que o "ser é e não pode não ser", dirá Platão: o uno é e é necessário que seja o mesmo que si mesmo, diferente dele mesmo, diferente de e o mesmo que os outros. Como entendermos melhor esta aparente contradição? Com respeito à primeira característica, ser o mesmo, não há muito que pensar, ou seja, o uno não é diferente de si mesmo, posto que se fosse, guardaria uma relação ou bem da parte ao todo, ou bem, do todo à parte, coisa que vimos que não ocorre. 0 uno é idêntico a ele mesmo, mas por estar ao mesmo tempo em si mesmo e em outro é diferente. Diz Platão:

- 0 que estando no mesmo lugar que si mesmo, está em outra coisa diferente de si mesmo, não é necessário que seja ele mesmo diferente de si mesmo, já que está também em outro lugar diferente? (146c)

Como vimos anteriormente, o uno está em si mesmo enquanto totalidade de partes, mas está em outro enquanto todo. 0 argumento da diferença consiste em mostrar que dependendo do ponto de vista, o uno é e não é o mesmo, posto que tem aspectos distinguíveis, ou seja, é distinto como um todo e como a totalidade de suas partes e mais, se dissermos que o uno tem o caráter de distinto, implica na existência de algo que o faz diferente de, sendo assim, as coisas que são não uno têm que ser diferentes del uno e consequentemente o uno é diferente dos outros ${ }^{13}$.

Mas o que significa ser o mesmo que e ser diferente de? É possível que o idêntico esteja no diferente? Segundo Platão, a mesmidade em si e a diferencia são contrárias e, assim, "autodestrutivas", melhor dizendo, se a mesmidade nunca está no que é diferente, nem muito menos, a diferencia no que é o mesmo, visto que não há nada que seja, no qual a diferencia esteja presente durante um período de tempo (146d) não são estes que fazem com que o uno seja diferente dos não-unos, ou os "não-unos" do uno. Estaríamos diante de um paradoxo do tipo cético ou sofístico? retornemos ao texto, diz o filósofo: não há nada que seja, em que a diferença esteja presente. Aqui se pode perguntar: ao afirmar a impossibilidade de participação entre a diferença e a mesmidade em uma mesma coisa, não estaria Platão afirmando justamente a unidade e a mesmidade de cada coisa? Segundo Cornford Platão nessa passagem, faz referência a uma certa diferença interna das coisas, ou seja, cada coisa é uma e a mesma até que apareça uma diferença interna, nesse caso a se converte em $b$ (CORNFORD, 1989, p.238). De modo que o uno será semelhante e dessemelhante aos outros, semelhante por ser diferente, dessemelhante por ser o mesmo. Diz o texto:

- Quando dizemos, pois, que as outras coisas são diferentes do uno e que o uno é diferente das outras coisas, ao dizer duas vezes $<$ diferente $>$ não designamos a nenhuma outra coisa mais que aquela natureza a qual pertence esse nome. (147 e)

É evidente que do ponto de vista conceitual o uno e os outros são o mesmo, posto que têm 0 mesmo caráter. 0 uno, entendido nesses termos tem e não tem contato consigo mesmo e com os outros. Superada a noção do uno da hipótese primeira, Platão segue investigando as implicações derivadas de uma ideia de um uno que tem figura, que ocupa espaço e que, consequentemente, mantém relações consigo mesmo e com outros. 
0 ponto de partida da análise consiste em pensar o uno conforme os dois aspectos descritos na passagem $145 \mathrm{e}$, onde se afirma que o uno pode ser compreendido a partir dos aspectos distintos, a saber: como um todo e como a totalidade de suas partes. Para Platão, a única possibilidade que exclui o contato do uno tanto consigo mesmo, visto que suas partes enquanto totalidade, chegam ao seu limite, bem como, individualmente, enquanto seresunos e portanto, em contacto uns com os outros, é aceitar o dogma eleático do ser uno contínuo. Diz ele:

- Em consequência, as outras coisas não são nem uno nem dois nem tem o nome de nenhum outro número.

- Não.

- Portanto, só o uno é uno e não poderá haver dualidade.

- Parece que não.

- Não havendo dois, não há contato (149d).

Platão conclui a segunda hipótese, demonstrando como o uno que é tem existência e pode ser objeto de conhecimento e discurso. Contrariando o ser uno parmenídico do poema, o uno que é possui todos os caracteres e pode, sob distintos pontos de vista, tanto ser uno como múltiplo ${ }^{14}$.

- Mas se é uno e múltiplo e chega a ser e perece, acaso não é certo que quando chega a ser uno deixa de ser múltiplo, e quando chega a ser múltiplo deixa de ser uno? Para ser uno, é preciso que seja combinado, $e$ ao chegar a ser múltiplo, separado.

- Sim, em efeito

- E, se chega a ser uno e múltiplo, não é necessário que se desagregue e que se agregue?(156b)

Uma das passagens mais importante do Parmênides para a compreensão neoplatônica da segunda hipótese como a segunda hipóstase (a inteligência) é a seguinte:

- E o um, como parece, sendo tal, participaria de uma configuração, quer seja ela reta, quer redonda, quer seja alguma configuração mista dessas duas.

- Com efeito, participaria (145b).
Resgatada a ideia de participação, a segunda hipótese assumirá, na filosofia procleana, um decisivo posto entre o uno, absolutamente transcendente, e o ser entendido, aristotelicamente, como pensamento que pensa a si mesmo (to noetó noerón).

\section{A inteligência (nous) como pensante e pensado.}

W. Beierwaltes define o caráter do espírito como "lugar das ideias" (topos gar auton ton (ton ideon ho nous) (BEIERWALTES, 1990, p.86). No fundo estamos tratando da síntese neoplatônica entre os pensamentos de Parmênides e de Aristóteles em que, "ser e pensar" e o "pensa-mento que pensa a si mesmo" são o mesmo" e, portanto, confluem no nous como unimultiplicidade característica da primeira processão, diz Proclo:

Todo espírito pensa a si mesmo. Mas, o espírito primordial não pensa mais que a si mesmo e, nele, inteligência e inteligível são numericamente um (kaì hèn kat'arithmòn hen toúto nous kaì noetón).

Esta é a grande diferença e, ao mesmo tempo, característica constitutiva de todas as hénades que derivam da primeira inteligência, ou seja, enquanto derivadas todas pensam a si mesmas, mas também ao que the precede. Nessa perspectiva, temos uma relação em que as inteligências são definidas por seus objetos contemplados e, neste sentido, haverá uma primeira inteligência que contemplará o uno em si.

A identificação da segunda hipótese do Parmênides com a inteligência segue a exigência de determinação do "espaço" próprio para as "ideias intelectuais" (tà noerà eide). Eliminada a possibilidade de que haja no uno algum tipo de pensamento, resta estabelecer a identificação das "ideias" com a inteligência. As formas platônicas, embora múltiplas em seus conteúdos, são unificadas pelo espírito que enquanto incorporal e imóvel, une de maneira indivisivel a multiplicidade (Elem. Theol. 171).

0 espírito é uma plenitude de ideias (pleroma eidonn) e, enquanto imóvel, permanece ligado
14. Estamos conscientes da problemática histórica acerca da divisão do Parmênides em 8 ou 9 hipótese. Particularmente a tradição inglesa representada por Taylor, Cornford, Ryle, só para citar os mais importantes, entende que do passo 155 e até $157 \mathrm{~b}$, constitui um apêndice conclusivo da segunda hipótese, de modo que, estes autores não aceitam a leitura neoplatônica defendida por Diès, Moreau e Chaurre de que estes parágrafos constituem uma hipótese distinta, precisamente, a terceira do sistema triádico plotiniano: a Alma do mundo e as almas particulares. Não adentraremos nesse tipo de discussão, na verdade, nosso intuito ao seguir a leitura do Parmênides de Cornford, tem um objetivo muito concreto, ou seja demonstrar a partir da análise das Enéadas e dos comentadores neoplatônicos, a originalidade, se é que não podemos dizer a fidelidade, da leitura plotiniana do Parmênides, bem como, a riqueza do texto platônico e suas múltiplas possibilidades de leituras. De modo que tomamos 0 texto de Cornford como caminho metodológico a ser superado quando adentramos na exegese neoplatônica. 
à eternidade o que permite que a processão, derivada deste princípio seja, por um lado imutável (essencialmente) e, por outro, múltiplo. Por esta razão torna-se compreensível a frase: "todo espírito é sob o modo noético o que the precede e o que the segue" (idem, 173). Cumpre observar que a participação dos seres se dá pela aptidão e não simplesmente pelo ser. Esta observação será decisiva para a tradição cristã posterior que sustentará a hierarquização da realidade a partir de uma "disposição" para a contemplação das ideias eternas que implica, necessariamente, um processo contínuo de exercício das virtudes. Entre a produção (poíesis) e o ato produtor (hen to poiein)

Se inteligível e espírito são idênticos e se o ser de cada espírito é idêntico ao seu pensamento, e se produz o que produz por seu ser e produz em virtude do ser que é, é por seu ato de pensar que cada espírito produzirá seus produtos (Elem. Theol. 174).

É clara a identificação entre "ser" e "pensamento" como atos constitutivos das processões que derivam do ato intelectivo originário que, não somente mantém o movimento gerador, mas mantém-se intrinsecamente presente no gerado. Dito de outro modo, o nous é o que torna inteligível todas as coisas. A inteligibilidade dos seres inteligiveis expressa a unidade transcendente-imanante de um uno que se faz múltiplo e que, por esta razão, é pensamento e ato de pensar ao mesmo tempo, sem confundir-se com os objetos de pensamento (tà noerà eidén).

0 postulado de uma "unidade distinta" em que as ideias, enquanto objetos do pensamento, não se confundem entre si, embora estejam todas unificadas na inteligência, fundamenta-se na participação, sem confusão, das ideias e o espírito que as envolve. Proclo define essa relação como uma compenetração sem intervalo (adiastátós). Diz ele:

0 princípio que envolve as ideias não possui nenhuma extensão, ele não está em uma parte e em outra a maneira dos seres extensos, mas é todo inteiro concentrado na indivisa unidade e no uno (Elem. Theo. 176).
Indubitavelmente é o regresso à imagem da esfera (he sphaira) parmenidica. 0 espírito como integração de todos os inteligíveis, como ressalta W. Beierwaltes, é a expressão de uma pluralidade unitária (plethos heniaion) ou unificada (henoménon), que tem no círculo sua expressão plástica máxima (BEIERWALTES, 1990, p.222). Vale dizer que estamos nos referindo a inteligência em sua forma mais elevada, ou seja, à inteligência primeira, dado que, cada inteligência participa de modo distinto das ideias, isto é, há uma distinção entre inteligências universais e particulares (Elem. Theol. 177) que conduz ao problema da participação hierárquica dos seres na unidade originária do mais ínfimos, intermediários, divinos (deuses) e intelectivos (hipóstases). Dito de outro modo, quanto mais próximo da unidade, mais unificada e universal são as inteligências. A consequência derivada desta afirmação é a existência de um “desnivel" entre as múltiplas formas de participação nas ideias. Entre as inteligências superiores e intermediárias há uma variação em que as primeiras, por estarem mais próximas do uno, são mais simples e, portanto, partícipe de um número menor de ideias.

Proclo, no Comentário ao Crátilo, expressa a raiz pitagórica dessa hierarquização. Vejamos esta passagem:

Em efeito, ao ser perguntado Pitágoras//qual é o mais sábio dos seres, responde: o número; e qual é o segundo em sabedoria: o que impõe os nomes das coisas. Com o número se referia á ordem inteligivel que abarca a pluralidade das formas intelectiva; pois ali o número em seu sentido primeiro// e próprio se fundamenta depois do Uno supra essencial, o qual procura todos os seres na medida de sua essência (Com. Crat.XVI,25).

Nesta outra vemos a referência direta ao Parmênides:

0 Parmênides nos faz recordar: $<$ dele (do uno) não há nem nome nem discurso. $E$ os primeiríssimos gêneros dos deuses inteligiveis e unidos ao Uno mesmo e chamados ocultos, têm muito de incognoscivel e inefável (Idem, LXXI, 32-20). 
Esta conclusão é indispensável para a formulação da terceira hipótese do Parmênides que acompanha a mesma argumentação formulada na segunda, ou seja, posto que a pluralidade deriva diretamente da noção de um uno que tem ser, não há nada que impeça a existência de uma pluralidade de corpos capazes de moverem e repousarem-se. Chegamos, com isso, a existência dos outros seres como consequência lógica derivada da existência de um ente que é uno-múltiplo; os outros formam uma pluralidade que participam da unidade formando uma totalidade onde cada parte é uma parte. Afirma Platão:

- Bem. Dado que existem outras coisas que o uno, o uno não é as outras coisas; pois, do contrário, estas não seriam outras que o uno.

- É certo.

- Mas, no entanto, as outras coisas não estão completamente privadas do uno, mas de algum modo participam dele.

- De que modo?

- Porque as outras coisas que o uno são outras por terem partes; se, em efeito, não tivessem partes, seriam absolutamente um uno.

Os outros do uno são, assim, uma pluralidade definida que forma um todo completo. A unidade platônica, como bem ressalta Wahl, é uma unidade múltipla, que não destrói a existência das coisas sensíveis (WAHL, 1951, p.179). A unidade é o que concede limite à multidão ilimitada da pluralidade, ou dito de outra maneira, toda coisa na medida em que é, admite uma variação entre um mais e um menos. A essa variante Platão chamou de díada indefinida, uma variação de magnitudes infinitivamente divisíveis. Vale dizer que "multidão" se refere de forma abstrata a algo que não possui unidade, posto que é a unidade que impõe limite ao ilimitado fazendo com que "o que é outro do uno" exista. Diz ele:

No entanto, uma vez que cada parte, uma por uma, chegou a ser parte, tem, cada uma delas, em efeito, um limite em relação as outras e em relação ao todo, e assim, também, tem um limite o todo com respeito às partes. (158d)

\section{A título de conclusão}

De modo que dada a existência de outras realidades distintas do uno, estas possuem todos os caracteres expostos na hipótese segunda, ou seja, serão semelhantes e dessemelhantes, estarão em movimento e em repouso e têm todos os caracteres contrários, superando, assim, a visão eleática que eliminava a possibilidade de que algo existisse ao lado do ser uno. Para Proclo, esta passagem é a prova de que Platão fala aqui da geração que culminará no mundo sensível mediante a processão do uno. Um fato importante desta hipótese é que Platão fundamenta, de uma maneira clara, a participação das coisas individuais na unidade, ou seja, o que faz com que uma coisa participe da unidade não é possuir uma parte ou o todo da forma unidade, mas o elemento de limite imposto, como dissemos anteriormente, a uma natureza ilimitada (CORNFORD, 1989, p.301). Seguindo a análise de J. Wahl, podemos dizer que na terceira hipótese temos uma tentativa de unir as conclusões retiradas das duas primeiras, ou seja, na terceira hipótese, se é correta a afirmação de Wahl, temos o múltiplo nascendo do uno e o uno nascendo do múltiplo, mas mediado por algo que transcende as contradições existentes entre a primeira e segunda hipóteses.

0 uno da terceira hipótese teria, assim, um aspecto que o situa entre a inefabilidade do primeiro uno e a eternidade do segundo, a saber, a instantaneidade. 0 instante é o espaço em que a visão racional se confunde com a visão do bem abrindo a possibilidade concreta de se pensar uma questão que só será definida, no Parmênides, na quarta hipótese, a saber: o infinito (WAHL,1951, p. 171). Entretanto, nos Elementos de Teologia, Proclo, seguindo a estrutura triádica, finaliza sua obra expondo, exatamente, a participação das almas nas inteligências. A introdução de um uno que é, ao mesmo tempo, uno e múltiplo, é o coroamento de uma filosofia que tem na epistrophé a consumação e realização de um "sistema" organizado a partir da geração infinita de um uno que transcende, de modo absoluto, mas que se mantém como ser e pensar, dado que é causa e razão, imanente em todas as coisas. A alma é, assim, não somente 
imagem de um princípio racional, mas espaço de realização e reconhecimento de que cada porção ínfima da natureza expressa a unidade vivificante que, em última instância, é a vida em sua completa manifestação. Por essa razão, torna-se imprescindível a participação das almas no espírito. Diz Proclo: “Pois a divindade coopera com o espírito para que a alma, beneficiada pela participação, realize a conexão entre o divino e o divino ".

\section{Referências bibliográficas}

BEIERWALTES, W. Pensare l'Uno, studi sulla filosofía neoplatonica e sulla storia dei suoi influssi, traduzione Maria L. Gatti, Milano: Vita e Pensiero, 1992.

Proclo. I fondamenti della sua metafísica, traduzione Nicoletta Scotti, Milano: Vita e Pensiero, 1990.

- Identità e differenza, traduzione Salvatore Saini, Milano: Vita e Pensiero, 1989.

BEZERRA, C.C. Compreender Plotino e Proclo, Vozes: Petrópolis, 2006.
CORNFORD, F.M. Platón y Parménides, trad. Francisco G. García, Madrid : Visor, 1989.

WAHL, J. Étude sur le Parménides de Platón, Paris: J. Vrin, 1951.

TROUILlard, J. Proclus, Éléments de Théologie, Paris: Aubier-Montaigne, 1965

MARINUS, Vie de Proclus, trad. A.-ED. Chaignet in: Proclus, Commentaire sur Le Parmènide, Paris: Minerva, Tomo Premier, 1900.

PACI, E. Il significato del Parmenide nella filosofía di Platone, Messina: Giuseppe Principato, 1938.

PLATÃo. Parmênides, trad. Maura Iglésias e Fernando Rodrigues, Rio de Janeiro: PUC/RJ-Loyola, 2003.

Parmênides, trad. Guillermo R. de Echandía, Madrid: Alianza, 1990.

CEuvres completes, trad. Auguste Diès, Paris: Les Belles Lettres, 1950.

PROCLO. Commentaire sur Le Parménides, trad. A.-ED. Chaignet, Paris: Minerva, Tomo Premier, 1900.

Lecturas del Crátilo de Platón, trad. Jesús Ma Álvarez et allí. Madrid: Akal, 1999.

Élements de Théologie, trad. Jean Trouillard, Paris: Aubier, 1965.

Élementos de teología, trad. Francisco de P. Samaranch, Buenos Aires: Aguilar, 1965. 